\title{
A Solar-Driven Flexible Electrochromic Supercapacitor
}

\author{
Danni Zhang, Baolin Sun, Hui Huang, Yongping Gan, Yang Xia, Chu Liang, Wenkui Zhang and \\ Jun Zhang *(1) \\ College of Materials Science and Engineering, Zhejiang University of Technology, Hangzhou 310014, China \\ * Correspondence: zhangjun@zjut.edu.cn
}

Received: 5 February 2020; Accepted: 5 March 2020; Published: 9 March 2020

check for updates

\begin{abstract}
Solar-driven electrochromic smart windows with energy-storage ability are promising for energy-saving buildings. In this work, a flexible photoelectrochromic device (PECD) was designed for this purpose. The PECD is composed of two flexible transparent conductive layers, a photocatalytic layer, an electrochromic material layer, and a transparent electrolyte layer. The photocatalytic layer is a dye-sensitized $\mathrm{TiO}_{2}$ thick film and the electrochromic layer is a $\mathrm{WO}_{3}$ thin film, which also possesses a supercapacitive property. Under illumination, dye-sensitized $\mathrm{TiO}_{2}$ thick film realizes photo-drive electrochromism that the $\mathrm{WO}_{3}$ changes from colorless to blue with large optical modulation. Meanwhile, the PECD has an electrochemical supercapacitance showing an energy storage property of $21 \mathrm{mF} \cdot \mathrm{cm}^{-2}\left(114.9 \mathrm{~F} \cdot \mathrm{g}^{-1}\right.$ vs the mass of $\left.\mathrm{WO}_{3}\right)$, stable mechanical performance and long cycle performance. The PECD can effectively adjust the transmittance of visible and near-infrared light without any external power supply, realizing zero energy consumption, and can convert solar energy into electrical energy for storage.
\end{abstract}

Keywords: photoelectrochromic devices (PECD); dye-sensitized solar cells (DSSC); electrochromic devices (ECD); smart windows; flexible devices

\section{Introduction}

The negative impact of traditional energy consumption on the environment has aroused great social concerns. According to relevant calculations, the annual energy consumption of buildings accounts for about $40 \%$ of the world's total energy consumption [1]. In addition, doors and windows are the most serious parts of a building's energy loss and their energy consumption accounts for a large proportion of the total energy consumption of buildings [2]. Currently, the widely used low-emission (Low-E) glass can limit the heat exchange between the indoor and the outdoor environments [3], but it cannot realize the continuous regulation of light. Therefore, it is urgent to develop new green smart windows with low energy consumption and a large optical modulation range.

Electrochromic devices (ECDs) can produce a reversible color change when charge insertion/extraction or chemical reduction/oxidation processes occur under electrochemical stimulation [4-6]. The features of ECDs make it have great application potential not only in smart windows [7-9], but also in anti-glare rearview mirrors [10], displays [11] and encryption devices [12]. In order to obtain a better performance, including contrast ratio [13], coloration efficiency (CE) [14], response time [15] and cycle life [16], a transparent electrode is required to have a low sheet resistance, high transmittance, stable electrochemical performance, stable mechanical performance and a high Figure of Merit (FoM, the ratio of electrical conductivity $\sigma_{C V}$ and optical conductivity $\sigma_{O P}, \sigma_{C V} / \sigma_{O P}$ ) [17]. Traditional electrodes are rigid, such as indium tin oxide (ITO) [18] or fluorine-doped tin oxide (FTO) [19] glass. However, their applications are limited by their disadvantages, such as their high price, their being difficult to carry and their unbending properties. Therefore, researchers pay attention to flexible ECDs $[20,21]$ made with flexible transparent electrodes. For example, ITO [22], metallic 
nanowires/grids ( $\mathrm{Ag}, \mathrm{Au}$ ) [23,24], carbon nanotubes [25], graphene [26], and conductive polymers [27] on flexible substrates. ITO, with its high transmittance and low sheet resistivity, has become one of the most common electrodes. In addition, electrochromic materials are very significant for ECDs. Transition metal oxide $\mathrm{WO}_{3}$ [28-30] has been widely studied due to its excellent electrochemical and electrochromic properties. With the intercalating of metal cation, $\mathrm{W}^{6+}$ is reduced to $\mathrm{W}^{5+}$ and $\mathrm{W}^{4+}$, causing the color to change from colorless to blue.

However, conventional ECDs do not change color automatically and require an external power source to achieve electrochromism [31,32], which is not easy to carry and is associated with energy consumption. Solar cells can convert solar energy into electric energy and are environmentally friendly. By connecting solar cells with ECDs, photoelectrochromism can be realized [33]. The basic components of photo-drive ECDs mainly include photovoltaic modules and electrochromic modules, which are roughly divided into two types. In the first type, photovoltaic modules and electrochromic energy storage modules are independent of each other and are connected by external circuits. Photovoltaic modules convert solar energy into electric energy so that they can charge for electrochromic modules and drive the color changing, which can be referred to as photovoltaic electrochromic devices (PV-ECDs). For example, Xia et al. [34] connected perovskite solar cells with electrochromic devices with wires so that solar cells could supply power to ECDs, realizing solar energy capture, electrochemical energy storage, electrochromism and recycling. In the second type, photovoltaic modules and electrochromic energy storage modules are integrated into one device, and the electrolyte is shared by the two modules. No external circuit connection is required, simplifying the device structure, which can be referred to as photoelectrochromic device (PECDs). For example, Leftheriotis et al. $[35,36]$ designed "Partly covered" photoelectrochromic devices by integrating dye-sensitized solar cells and an ECD into one device, which showed enhanced coloration speed and efficiency. Xu et al. [37] designed an optically driven ECD, which integrates a large area of electrochromic parts with several small fiber-like DSSCs, and can optimize the optical drive power by means of series or parallel photovoltaic modules to achieve photo-driven electrochromism. In addition, Tong et al. studied [38] the possibility of integration between electrochromic devices and photovoltaic devices and structures for photoelectrochromic devices. However, photoelectrochromic devices studied are almost always rigidly based on FTO/ITO glass and flexible devices are rare.

In this work, we combined the DSSC with the ECD based on $\mathrm{WO}_{3}$ electrochromic material in a horizontal way to form a flexible PECD. Our structure is not only simpler and more integrated than the traditional ECDs, but also does not require an external power source. The DSSC module will convert the solar energy into electricity to charge the ECD module under illumination and achieve photoelectrochromism realizing zero energy consumption. It provides solutions for achieving low-energy green buildings. Compared with ordinary windows, this PECD can intelligently adjust the transmittance of the visible band and near-infrared band in the sunlight, thus effectively regulating indoor visibility and temperature. Moreover, this flexible feature can make it suitable for various shapes of glass and any place. In addition, the electrochromic module can also store energy and be used as a supercapacitor.

\section{Materials and Methods}

\subsection{Materials and Reagents}

Indium tin oxide-polyethylene glycol terephthalate (ITO-PET) substrates (sheet resistance $35 \Omega \cdot \mathrm{sq}^{-1}$, transmittance $>82 \%$ ) were purchased from Zhuhai Kaivo Optoelectronic Technology Co., Ltd. (Zhuhai, China). W target was purchased from Hefei Kejing Materials Technology Co., Ltd. (Hefei, China). Iodine (AR, 99.8\%), lithium iodide (99\%) and propylene carbonate (PC, 99.7\%) were purchased from Aladdin (Shanghai, China). Di-tetrabutylammonium cis-bis (isothiocyanato) bis (2,2'-bipyridyl-4,4'-dicarboxylato) ruthenium (II) (N719, > 95\%) and surlyn sealing films $(60 \mu \mathrm{m})$ were purchased from Opv-Tech Co., Ltd. (Yingkou, China). N,N-dimethylformamide (DMF, 99.5\%) 
was purchased from Xilong Scientific Co., Ltd. (Shantou, China). Tetrabutyl titanate (CP, 98.0\%) was purchased from Shanghai Lingfeng Chemical Reagent Co., Ltd. (Shanghai, China). Poly (vinylidene fluoride-co-hexafluoro propylene) (PVDF-HFP, Arkema 2801) and $\mathrm{TiO}_{2}$ (Degussa P25) were used without further treatment.

\subsection{Fabrication of the Photoanode and Counter Electrode}

The commercial ITO-PET substrates were first cleaned with ethyl alcohol and deionized water sequentially. The precleaned substrates were then dried in the oven. The $\mathrm{TiO}_{2}$ film was prepared by the doctor-blade method; the specific steps are as follows: First, $1 \mathrm{~g} \mathrm{TiO} 2$ powder and several drops of tetrabutyl titanate were added into $4.4 \mathrm{~mL}$ ethyl alcohol with stirring for $24 \mathrm{~h}$. Second, tape was pasted on both sides of the reserved DSSC part and excessive $\mathrm{TiO}_{2}$ colloid was dropped, and then manually scraped with the smooth side of FTO glass until the surface of the $\mathrm{TiO}_{2}$ film was smooth and uniform. After the ethanol was volatilized at room temperature, the by-product alcohols were removed by heat treatment at $120^{\circ} \mathrm{C}$ for $2 \mathrm{~h}$. Finally, $20 \mathrm{MPa}$ pressure was applied to increase the adhesion between the $\mathrm{TiO}_{2}$ film and the substrate.

Pt electrode was obtained by vacuum sputtering for $45 \mathrm{~s}$, presenting a transparent light gray color.

\subsection{Preparation of $\mathrm{WO}_{3}$ Thin Film}

The $\mathrm{WO}_{3}$ film was coated on the same ITO-PET substrate by the DC magnetron sputtering method, parallel to $\mathrm{TiO}_{2}$ film. First, the $\mathrm{TiO}_{2}$ film prepared above was covered by a mask to prevent coating the $\mathrm{WO}_{3}$. Then, the $\mathrm{WO}_{3}$ film was prepared in an atmosphere of pure argon and oxygen gases with a flow ratio of $2: 1$, power of $115 \mathrm{~W}$, pressure of $0.7 \mathrm{~Pa}$ and sputtering time of $40 \mathrm{~min}$. Finally, the $\mathrm{TiO}_{2} / \mathrm{WO}_{3} / \mathrm{ITO}-\mathrm{PET}$ electrode was immersed into $0.5 \mathrm{mM}$ N719 in ethanol for $24 \mathrm{~h}$.

\subsection{Fabrication of the Electrolytes}

Preparation of the membrane: Firstly, PVDF-HFP was dissolved in DMF solvent with a mass ratio of 3:7 and heated at $60^{\circ} \mathrm{C}$ for $24 \mathrm{~h}$ to fully dissolve PVDF-HFP. Then, PVDF-HFP was scraped evenly on the glass and transferred into water to obtain a film. Finally, it was put into a vacuum oven at $80{ }^{\circ} \mathrm{C}$ to dry.

Preparation of Electrolyte: 0.5 M LiI and 0.005 $\mathrm{M} \mathrm{I}_{2}$ were dissolved in PC solvent and stirred for $24 \mathrm{~h}$. The prepared membrane was cut to a suitable size and soaked in electrolyte for $24 \mathrm{~h}$.

\subsection{Fabrication of the PECD}

PECDs are composed of the $\mathrm{WO}_{3} / \mathrm{TiO}_{2} / \mathrm{ITO}-\mathrm{PET}$ electrode, electrolyte and a Pt counter electrode. First, a suitably sized electrolyte membrane was applied to the $\mathrm{WO}_{3} / \mathrm{TiO}_{2} / \mathrm{ITO}-\mathrm{PET}$ electrode, followed by a surlyn sealing film around the electrolyte membrane, and then a Pt electrode was covered. Second, copper tape was attached to the side of the ITO-PET and pulled out for electrical conductivity. At last, it was put into card films and overplasticized.

\subsection{Characterization}

The structural properties of $\mathrm{WO}_{3}$ films were characterized by X-ray diffraction (XRD, Rigaku Ultima IV, Tokyo, Japan). The surface morphology and crossing morphology of the films were characterized by field emission scanning electron microscopy (FESEM, Hitachi S4700, Tokyo, Japan). The ultraviolet-visible-near-infrared (UV-VIS-NIR) transmission spectra of the assembled devices were characterized using a UV-3600 spectrophotometer. The electrochemical performance of the assembled devices was characterized by the Zennium electrochemical workstation (ZAHNER, Kronach, Germany). 


\section{Results and Discussion}

The structural diagram and schematic diagram are shown in Figure 1. The PECD has a sandwich structure [39] consisting of the DSSC module and the ECD module. In Figure 1a, the DSSC module is composed of the ITO-PET electrode, electrolyte, $\mathrm{TiO}_{2}$ film and the Pt electrode, and the ECD module is composed of the ITO-PET electrode, electrolyte, $\mathrm{WO}_{3}$ film and the Pt electrode, which share the ITO-PET electrode, electrolyte and the Pt electrode. The size of the electrode is $3.5 \mathrm{~cm} \times 2 \mathrm{~cm}$, in which the magnetron sputtering $\mathrm{WO}_{3}$ film is $2 \mathrm{~cm} \times 2 \mathrm{~cm}$, the $\mathrm{TiO}_{2}$ film is $0.5 \mathrm{~cm} \times 2 \mathrm{~cm}$, and the extra part was used for sticking copper tape. Figure $1 b, c$ illustrates the coloring and bleaching principle of the PECD, respectively. When the device is exposed to the light, the dye molecules are excited to generate electron hole pairs, and the electrons are injected into the $\mathrm{TiO}_{2}$ conduction band, and then diffused to the ITO-PET substrate and $\mathrm{WO}_{3}$. In order to neutralize the electrons enriched in $\mathrm{WO}_{3}, \mathrm{Li}^{+}$ in electrolyte is intercalated in $\mathrm{WO}_{3}$, and redox reaction occurs, causing $\mathrm{WO}_{3}$ to turn from colorless to blue. The PECD in this state can block most incident light. At the same time, the dye loses electrons and is reduced by $\mathrm{I}^{-}$to realize dye regeneration. When the device is in short circuit or connected with external electrical appliances, the co-deintercalation of electrons and $\mathrm{Li}^{+}$occurs, making $\mathrm{WO}_{3}$ change from blue to colorless. The PECD in this state allows most of the incident light to pass through. At the same time, the oxidized electrolyte is reduced after receiving electrons at the Pt electrode, thus completing the cycle. The schematic reaction can be summarized as the equation below:

$$
\begin{gathered}
{\left[\mathrm{WO}_{3}+\mathrm{xLi}^{+}+\mathrm{xe}^{-}\right]_{\text {bleached }} \leftrightarrow\left[\mathrm{Li}_{\mathrm{x}} \mathrm{WO}_{3}\right]_{\text {colored }}} \\
\mathrm{I}^{-} \leftrightarrow \mathrm{I}_{3}^{-}
\end{gathered}
$$

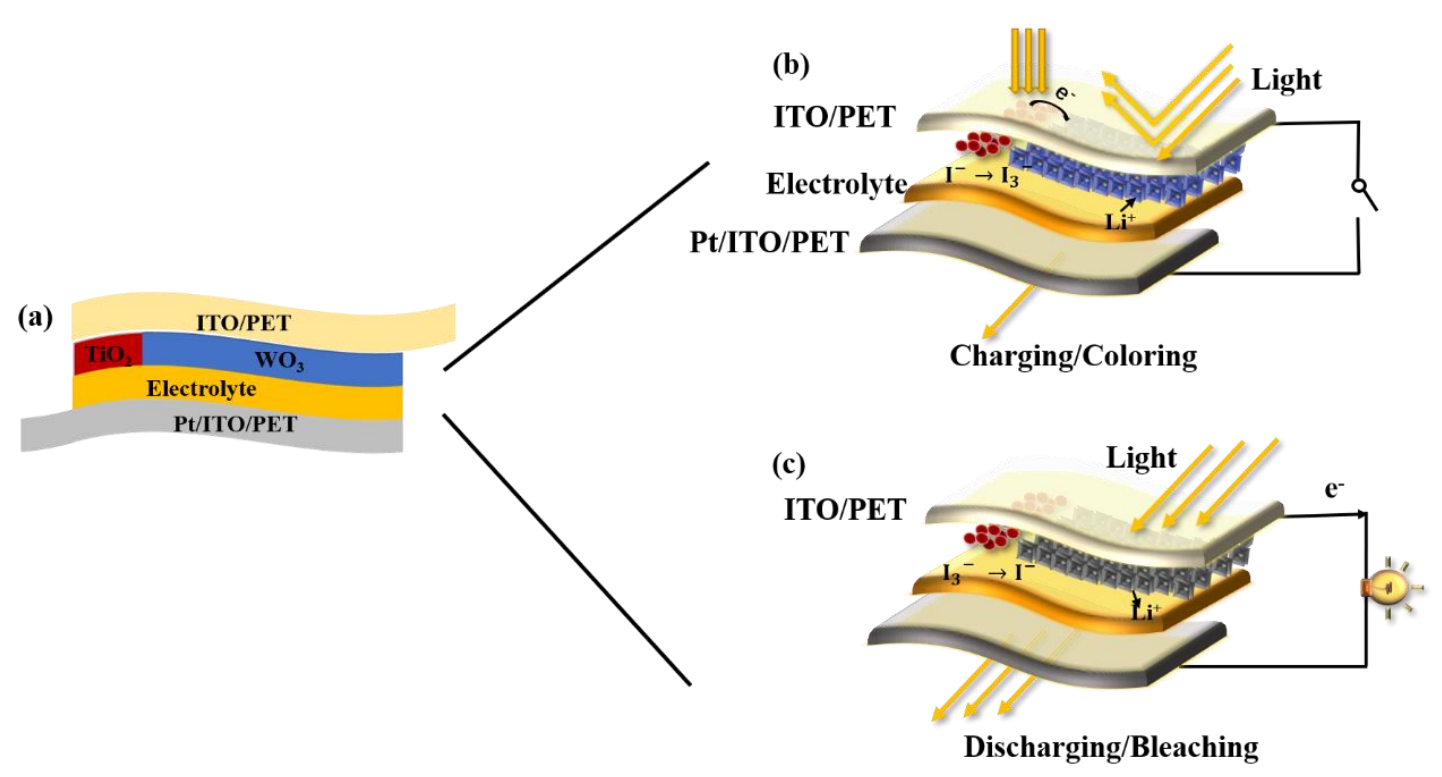

Figure 1. Schematic diagrams of the photoelectrochromic device (PECD); (a) photo-charging process of the PECD and (b) the discharging process of the PECD (c). 
To better understand the structures and morphology of $\mathrm{WO}_{3}$ films, FESEM and XRD tests were performed. The surface morphology of $\mathrm{WO}_{3}$ films is shown in Figure $2 \mathrm{a}$. $\mathrm{WO}_{3}$ is distributed compactly on the substrate and agglomerated. The thickness of the sputtered $\mathrm{WO}_{3}$ over ITO-PET is estimated at about $600 \mathrm{~nm}$, as shown in Figure 2b. In Figure 3, XRD has no characteristic peak of $\mathrm{WO}_{3}$, indicating that $\mathrm{WO}_{3}$ obtained by magnetron sputtering is amorphous. Amorphous tungsten oxide films usually have a higher coloration efficiency and faster switching time [40,41].

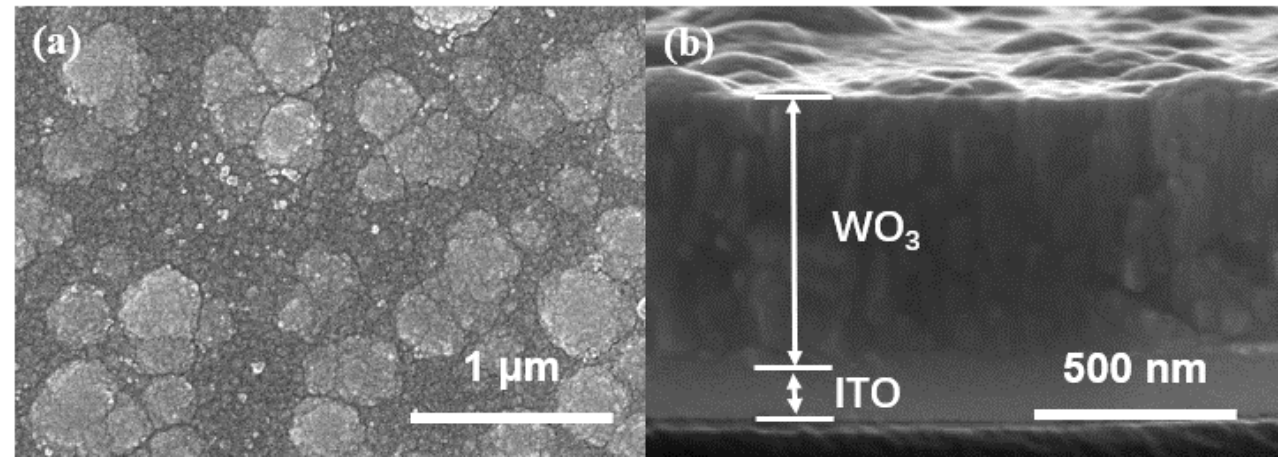

Figure 2. (a) Field emission scanning electron microscopy (FESEM) images of the $\mathrm{WO}_{3}$; (b) FESEM image of the thickness of the $\mathrm{WO}_{3}$.

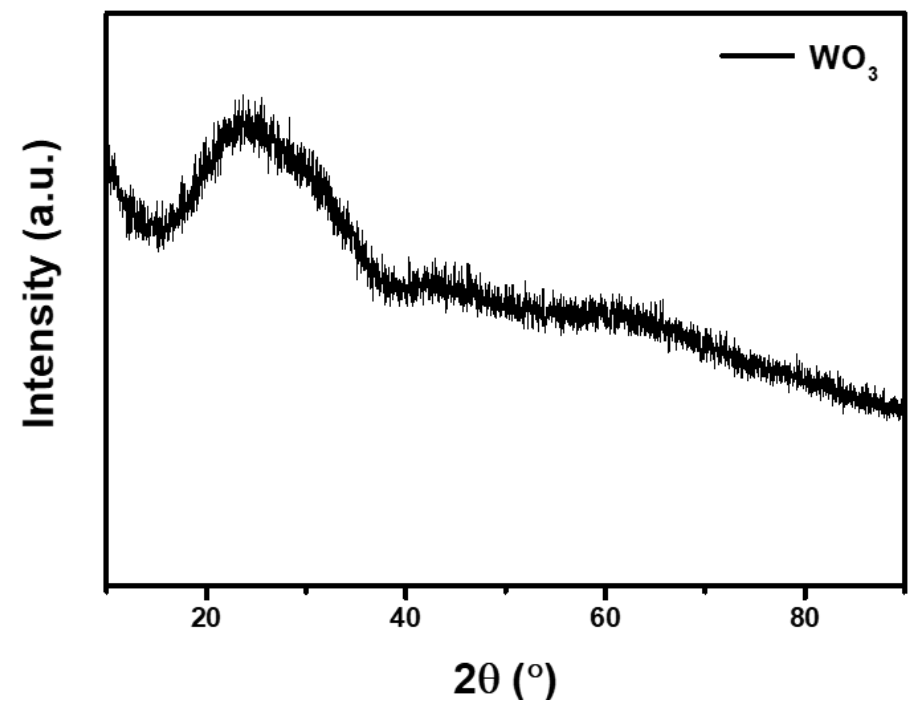

Figure 3. XRD pattern of the obtained $\mathrm{WO}_{3}$.

In the PECD, the DSSC shares the same electrolyte with the ECD, so it is important to design a suitable electrolyte to support them. To get a higher ionic conductivity of the electrolyte, we prepared a PVDF-HFP membrane infiltrating liquid electrolyte and gel electrolyte with PVDF-HFP as gels. Supplementary Materials Figure S1 shows EIS of the PVDF-HFP membrane infiltrating liquid electrolyte and PVDF-HFP gel electrolyte, and the former is about $270 \Omega$, smaller than the gel electrolyte, so the PECD with this PVDF-HFP membrane shows a better electrochemical and electrochromic performance. However, compared with the traditional DSSC, the ionic conductivity is still not ideal because the electrolyte concentration is reduced in order to increase the transmittance. As shown in Figure $4 \mathrm{a}$, the transmittance spectra of the bleached state and the colored state of the PECD were tested within the wavelength range of 300-1100 nm. The transmittance of the colored state was tested after being exposed to a $1000 \mathrm{~W}$ xenon lamp for $10 \mathrm{~min}$ and the transmittance of the bleached state was tested after applying $-1 \mathrm{~V}$ voltage for $3 \mathrm{~min}$. Compared with the bleached state, the transmittance of the PECD in the colored state decreases significantly, which can effectively block out near-infrared and visible light 
to regulate temperature and indoor visibility, indicating that it has great application potential in the field of smart windows. After 1000 cycles, the transmittance of the bleached state changes slightly, while that of the colored state increases significantly. The colored and bleached images of the first cycle and the 1000th cycle are shown in the illustration in Figure 4a. The precise transmittance values at $529 \mathrm{~nm}$ and $860 \mathrm{~nm}$ of the PECD are given in Table S1. Since the electrolyte is yellowish in color, the overall appearance of the device in the bleached state is yellowish. From Figure S2, we can see the photo of the PVDF-HFP membrane before and after the electrolyte immersion. The newly prepared membrane is thin and smooth, showing a white color. After electrolyte immersion, the membrane changes from white to transparent yellow and the transmittance increases significantly, so the optical effect on the electrolyte is negligible.

(a)

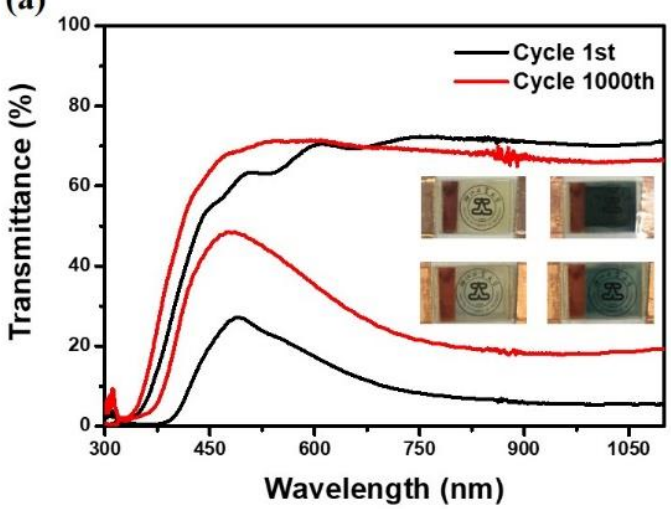

(b)

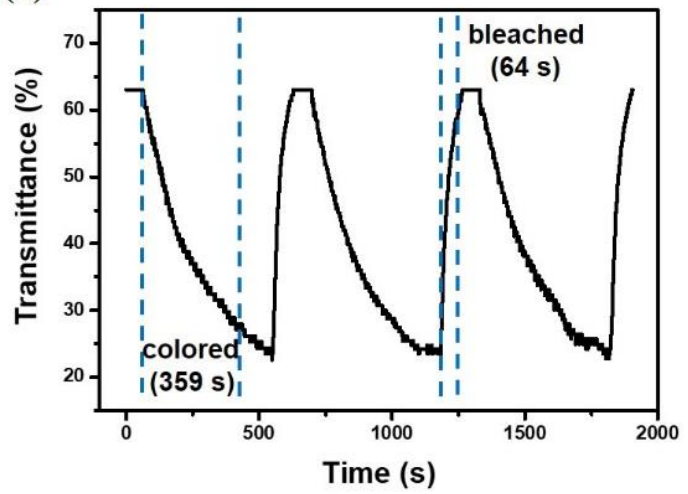

Figure 4. (a) The transmittance spectrum of the PECD in 300-1100 $\mathrm{nm}$ at the 1st cycle and the 1000th cycle; the insert corresponds to the 1st cycle bleaching and coloring state and the 1000th cycle bleaching and coloring state; (b) switching performance of the PECD at $529 \mathrm{~nm}$.

Switching time is usually an important parameter for ECDs and is defined as the spanning time required for a $90 \%$ change between the bleached and colored states. Green light at $529 \mathrm{~nm}$ was used as the light source, and the photosensitive resistor was used as the original test element. The light source, PECD, and photosensitive resistor were arranged in order at the same horizontal line. The DSSC module of the PECD was exposed while the ECD module, the light source and the photosensitive resistor were in the dark state. The relationship between the current and the time recorded by the photosensitive resistor was converted into the relationship between the transmittance (at $529 \mathrm{~nm}$ ) and time so as to obtain the switching time. The switching time of the PECD is shown in Figure 4b; the coloring time is slower than that of traditional electrochromic devices, $359 \mathrm{~s}$, and the bleaching time is $64 \mathrm{~s}$ when $-1 \mathrm{~V}$ voltage is applied. Four guesses about the slower switching time than traditional ECD are as follows: The impedance of the electrolyte is shown in the Figure S1, and the ionic conductivity of the electrolyte is not high. The J-V curve of the flexible DSSC is shown in Figure S3a, the short-circuit current density is $0.21 \mathrm{~mA} / \mathrm{cm}^{2}$, the open-circuit voltage is $0.63 \mathrm{~V}$, and the conversion efficiency is not ideal. The J-V curve of the PECD is shown in Figure S3b, the open circuit voltage is about $0.6 \mathrm{~V}$ and although it can drive $\mathrm{WO}_{3}$ from colorless to blue, it is low compared with the voltage applied by electrochemical workstations in other studies [42,43]. And it takes time for the PECD to reach sufficient voltage. In addition, compared with the traditional DSSC, the short-circuit current density of the PECD is not the maximum, which may be due to the addition of the ECD module, which undergoes redox reaction. 
Since the PECD of this structure can realize the optical regulation of near-infrared light, a model house was prepared to study the temperature control effect of the PECD. To prove that this PECD has the effect of temperature control compared with ordinary devices, the PECD in colored state and the $\mathrm{WO}_{3-}$ free device act as the window of the model house. As shown in Figure 5, the indoor temperature of the model house increases significantly when exposed to the infrared lamp. After $10 \mathrm{~min}$, the temperature rises at a steady rate. The indoor temperature of the window with the colored PECD is always lower than that of the window without $\mathrm{WO}_{3}$. In $15 \mathrm{~min}$, the indoor temperature increases from room temperature to $46.3^{\circ} \mathrm{C}$, while the other one increases from room temperature to $51.6^{\circ} \mathrm{C}$, which strongly proves that the PECD as a smart window has a good temperature control effect. Therefore, when the PECD is applied in real life, it can automatically change from a bleached state to a colored state on sunny days, reducing the transmittance of near-infrared light and achieving the effect of temperature control. In addition, the PECD can be changed from a colored to a bleached state by applying voltage when light is needed in the room.

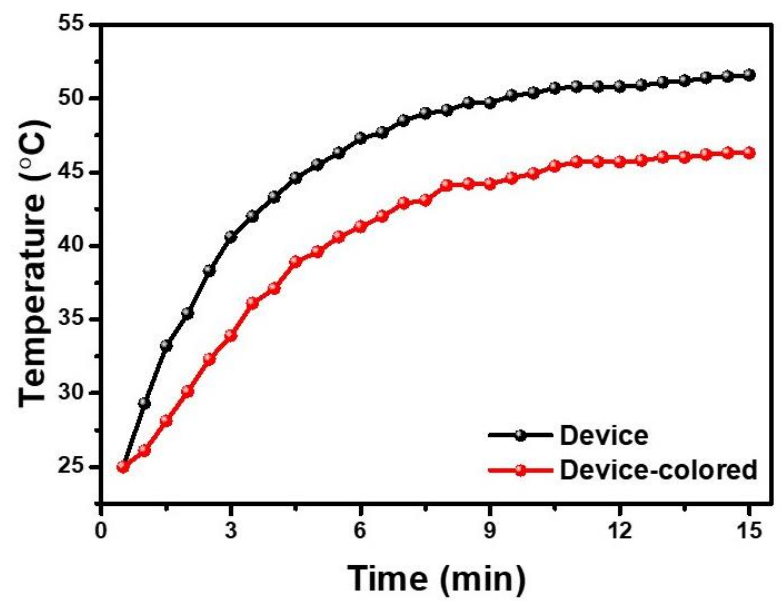

Figure 5. Temperature of the two rooms versus the infrared irradiation time, the windows of the room are made up of different devices.

The PECD can not only realize photo-drive electrochromic performance, showing excellent electrochromic performance, but also has a good electrochemical performance. Figure 6a shows the $\mathrm{C}-\mathrm{V}$ curve of the PECD between $-1.5 \mathrm{~V}$ and $1.5 \mathrm{~V}$ at the scan rate of $100 \mathrm{mV} \mathrm{s}^{-1}$ in the dark. Two redox pairs are found in the $\mathrm{CV}$ curve, corresponding to $\mathrm{Li}_{x} \mathrm{WO}_{3} / \mathrm{WO}_{3}$ and $\mathrm{I}_{3}{ }^{-} / \mathrm{I}^{-}$, respectively. Figure $6 \mathrm{~b}$ shows the photo charge curve of the PECD and the constant current discharge curves at the current density of $10,20,40,60,80,100 \mu \mathrm{A} \cdot \mathrm{cm}^{-2}$. The device can reach an open circuit voltage of $0.55 \mathrm{~V}$ at a light intensity of $1000 \mathrm{~W} \cdot \mathrm{m}^{-2}$ and the discharge time decreases with the increase of discharge current density. As an energy storage device, capacitance is very important to it. Areal capacitance and the specific capacitance of the PECD are shown in Figure $6 c$, and both areal capacitance and specific capacitance decrease with the increase of discharge current density. At $10 \mu \mathrm{A} \cdot \mathrm{cm}^{-2}$, the maximum capacitance is $21 \mathrm{mF} \cdot \mathrm{cm}^{-2}\left(114.9 \mathrm{~F} \cdot \mathrm{g}^{-1}\right)$ and the minimum capacitance is $13.6 \mathrm{mF} \cdot \mathrm{cm}^{-2}\left(75.7 \mathrm{~F} \cdot \mathrm{g}^{-1}\right)$ at $100 \mu \mathrm{A} \cdot \mathrm{cm}^{-2}$. Another important performance of the PECD is cycle stability. Figure $6 \mathrm{~d}$ shows the capacitance retention of the PECD after 1000 cycles at $20 \mu \mathrm{A} \cdot \mathrm{cm}^{-2}$ discharge current density. In the first two hundred cycles of the PECD, the capacitance decays rapidly, and in the later stage, it is relatively stable and drops slowly. Our guess is that there was some residual $\mathrm{Li}^{+}$in $\mathrm{WO}_{3}$ during the initial $\mathrm{Li}^{+}$ insertion and extraction process, which led to this result. In addition, a previous study has shown that the cycling ability of crystalline $\mathrm{WO}_{3}$ is better than that of amorphous $\mathrm{WO}_{3}$ [44]. After 1000 cycles, the capacitance is about $65 \%$ of the initial value. In addition, the PECD can be used as an energy storage device. As a conceptual demonstration, several PECDs are connected in a series to act as a 
power supply in Figure S4. When the PECDs are fully charged, the devices are deep blue and light up red LEDs.

(a)

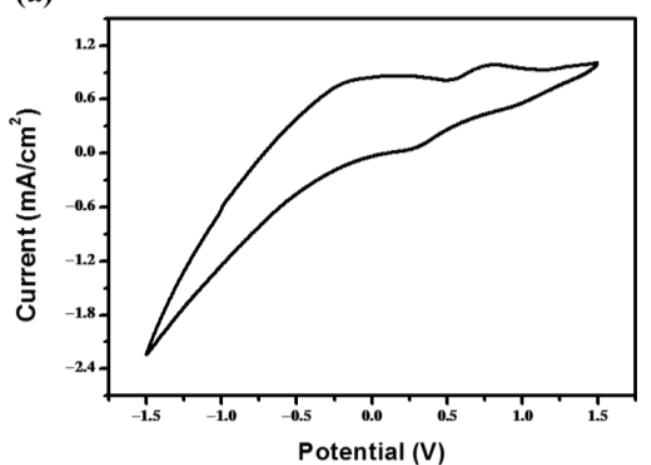

(c)

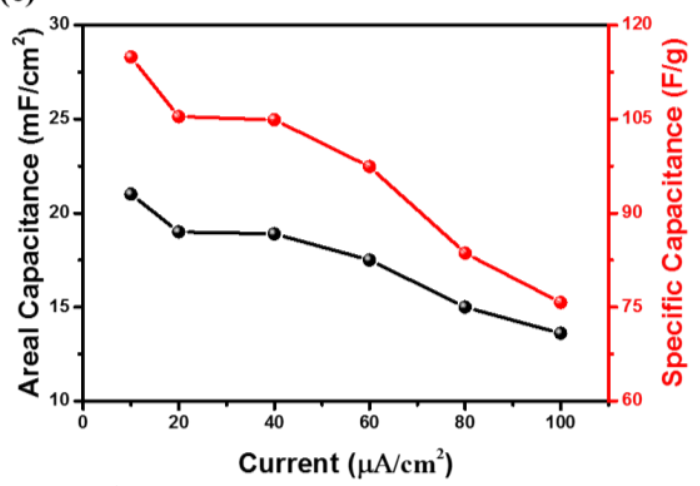

(b)

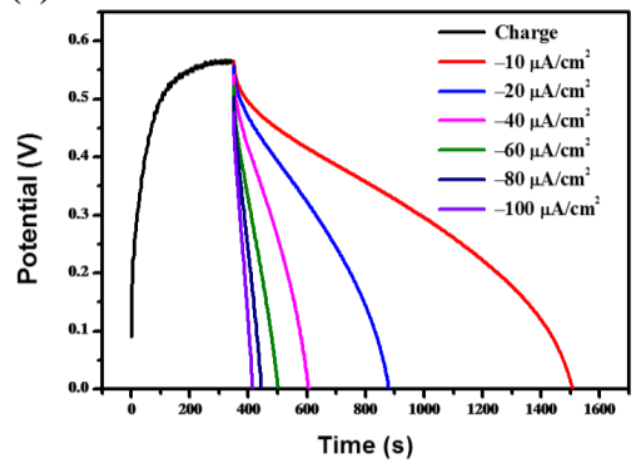

(d)

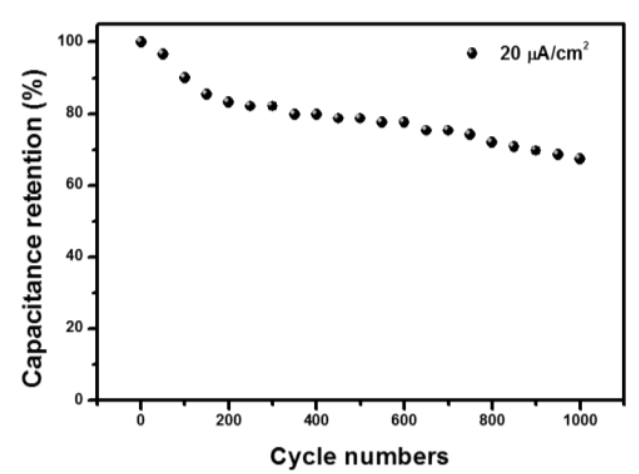

Figure 6. (a) The cyclic voltammetry curve of the PECD; (b) photo-charge curve and galvanostatic discharge curves of the PECD; (c) areal capacitances and specific capacitances of the $\mathrm{WO}_{3}$ film at different current densities; (d) cycle performance of the PECD under a current density of $20 \mu \mathrm{A} / \mathrm{cm}^{2}$.

The substrate of this device is ITO-PET. In contrast to traditional ITO and FTO glass, ITO-PET not only has a low sheet resistance and high transmittance, but also has excellent flexibility. In order to study the bending stability of the PECD, the PECD was bent, and the bending state is shown in Figure $7 \mathrm{~b}$. The $\mathrm{C}-\mathrm{V}$ curve of the PECD at the initial state and after bending 50 times was tested. As shown in Figure 7a, there is a slight difference between the CV curves, indicating that the PECD has a great bending stability. The amplification of the PECD has an enlightening effect on the later practical study. Now, the PECD is scaled up to four times. Figure 7c shows the bleached state of the enlarged PECD composed of the DSSC module on the left and the ECD module on the right. In addition, Figure $7 \mathrm{~d}$ shows the PECD on the human hand. In the bending state, the enlarged PECD can still be automatically colored under illumination, indicating its bending stability. Due to the smoothness and flexibility of the device, it can also be used in wearable applications. Furthermore, it is possible to implement smart windows of any shape and keep good performance. 
(a)

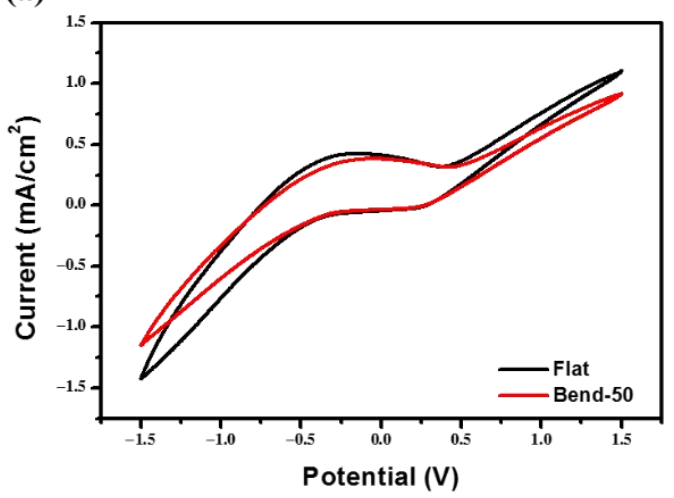

(c)

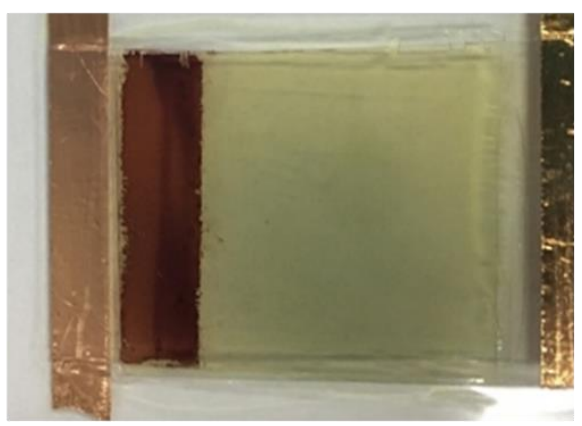

(b)

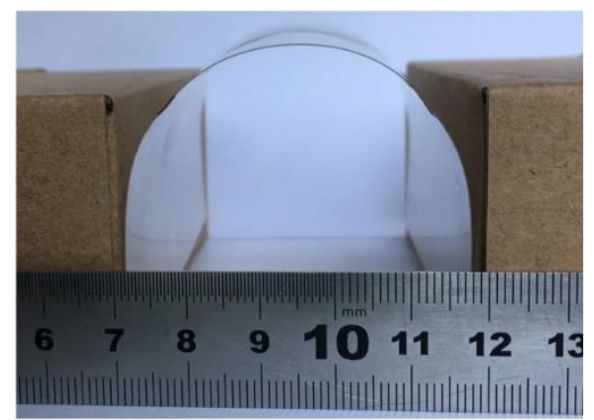

(d)

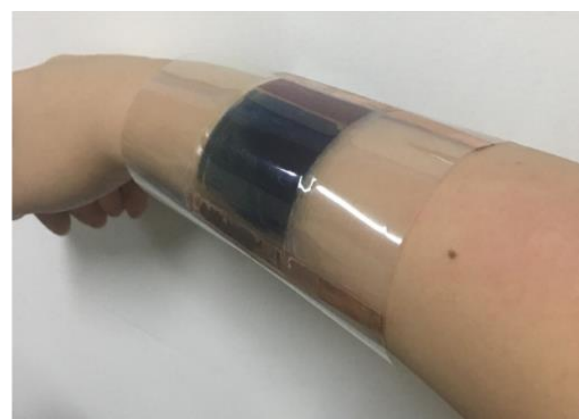

Figure 7. (a) The cyclic voltammetry curve of the PECD at the flat state and after 50 bends; (b) photograph of the bend state; (c) photograph of the enlarged PECD at the bleached state; (d) photograph of the enlarged PECD in the wearable field.

\section{Conclusions}

In summary, we successfully integrated the DSSC with the ECD using $\mathrm{WO}_{3}$ as electrochromic material to prepare a flexible PECD which shows excellent electrochromic performance and electrochemical performance. The switching time of the PECD is $359 \mathrm{~s}$ (coloring under illumination) and $64 \mathrm{~s}$ (bleaching under $-1 \mathrm{~V}$ voltage), respectively. Moreover, the optical modulation range of near-infrared light reaches more than $60 \%$. The maximum capacitance can reach $21 \mathrm{mF} \cdot \mathrm{cm}-2$ $\left(114.9 \mathrm{~F} \cdot \mathrm{g}^{-1}\right)$ and several PECDs connected in series can light up LEDs. At the same time, the enlarged device still exhibits a similar performance. However, due to the lack of understanding of the energy level matching of each functional component and photochemical reaction mechanism, PECDs are still rare, so the model needs to be further studied in order to realize the practical applications of the device in smart windows and other fields.

Supplementary Materials: The following are available online at http://www.mdpi.com/1996-1944/13/5/1206/s1. Figure S1. EIS spectra of the liquid electrolyte and gel electrolyte; Figure S2. The photograph of PVDF-HFP membrane before and after soaking electrolyte; Figure S3. J-V curves of DSSC (a) and PECD (b) under the irradiation of $1000 \mathrm{~W} / \mathrm{m}^{2}$; Figure S4. "ZJUT" composed by several red LEDs lit up by connected PECDs; Table S1. Transmittance properties of PECD at $529 \mathrm{~nm}$ and $860 \mathrm{~nm}$.

Author Contributions: Conceptualization, J.Z., H.H. and W.Z.; methodology, Y.G. and Y.X.; formal analysis, D.Z. and B.S.; data curation, D.Z. and C.L.; writing—original draft preparation, D.Z.; writing—review and editing, J.Z.; supervision, J.Z. and W.Z. All authors have read and agreed to the published version of the manuscript.

Funding: This research was funded by the National Natural Science Foundation of China (NSFC) under grant No. 51777194 and Zhejiang Provincial Natural Science Foundation of China under grant No. LR20E020002.

Conflicts of Interest: The authors declare no conflict of interest. 


\section{References}

1. Andric, I.; Pina, A.; Ferrao, P.; Lacarriere, B.; Le Corre, O. The impact of renovation measures on building environmental performance: An emergy approach. J. Clean. Prod. 2017, 162, 776-790. [CrossRef]

2. O'Grady, M.; Lechowska, A.A.; Harte, A.M. Application of infrared thermography technique to the thermal assessment of multiple thermal bridges and windows. Energy Build. 2018, 168, 347-362. [CrossRef]

3. Lin, S.; Wang, H.Y.; Zhang, X.N.; Wang, D.; Zu, D.; Song, J.A.; Liu, Z.L.; Huang, Y.; Huang, K.; Tao, N.A.; et al. Direct spray-coating of highly robust and transparent $\mathrm{Ag}$ nanowires for energy saving windows. Nano Energy 2019, 62, 111-116. [CrossRef]

4. Krebs, F.C. Careful design of donor-acceptor polymer molecules with reversible redox properties gives access to polymer electrochromic displays with switchable absorption in the full visible range of the optical spectrum. Nat. Mater. 2008, 7, 766-767. [CrossRef] [PubMed]

5. Yang, P.H.; Sun, P.; Mai, W.J. Electrochromic energy storage devices. Mater. Today 2016, 19, $394-402$. [CrossRef]

6. Madasamy, K.; Velayutham, D.; Suryanarayanan, V.; Kathiresan, M.; Ho, K.C. Viologen-based electrochromic materials and devices. J. Mater. Chem. C 2019, 7, 4622-4637. [CrossRef]

7. Zhao, Q.; Fang, Y.S.; Qiao, K.; Wei, W.; Yao, Y.J.; Gao, Y.F. Printing of $\mathrm{WO}_{3} / \mathrm{ITO}$ nanocomposite electrochromic smart windows. Sol. Energy Mater. Sol. Cells 2019, 194, 95-102. [CrossRef]

8. Xie, S.J.; Chen, Y.B.; Bi, Z.J.; Jia, S.S.; Guo, X.X.; Gao, X.D.; Li, X.M. Energy storage smart window with transparent-to-dark electrochromic behavior and improved pseudocapacitive performance. Chem. Eng. J. 2019, 370, 1459-1466. [CrossRef]

9. Zhai, Y.L.; Li, Y.; Zhang, H.; Yu, D.B.; Zhu, Z.J.; Sun, J.Z.; Dong, S.H. Self-rechargeable-battery-driven device for simultaneous electrochromic windows, ROS biosensing, and energy storage. ACS Appl. Mater. Interfaces 2019, 11, 28072-28077. [CrossRef]

10. Zhang, S.H.; Chen, S.; Yang, F.; Hu, F.; Zhao, Y.H.; Yan, B.; Jiang, H.; Cao, Y. A facile preparation of $\mathrm{SiO}_{2} / \mathrm{PEDOT}$ core/shell nanoparticle composite film for electrochromic device. J. Mater. Sci. Mater. Electron. 2019, 30, 3994-4005. [CrossRef]

11. Kateb, M.; Safarian, S.; Kolahdouz, M.; Fathipour, M.; Ahamdi, V. ZnO-PEDOT core-shell nanowires: An ultrafast, high contrast and transparent electrochromic display. Sol. Energy Mater. Sol. Cells 2016, 145, 200-205. [CrossRef]

12. Qiu, M.J.; Sun, P.; Zhang, B.; Yu, J.H.; Fu, Y.; Yu, X.; Zhao, C.X.; Mai, W.J. Reliable information encryption and digital display applications based on multistate smart windows. Adv. Opt. Mater. 2018, 6, 1800338. [CrossRef]

13. Kim, J.; Ong, G.K.; Wang, Y.; LeBlanc, G.; Williams, T.E.; Mattox, T.M.; Helms, B.A.; Milliron, D.J. Nanocomposite Architecture for Rapid, Spectrally-Selective Electrochromic Modulation of Solar Transmittance. Nano Lett. 2015, 15, 5574-5579. [CrossRef] [PubMed]

14. Ou, J.Z.; Balendhran, S.; Field, M.R.; McCulloch, D.G.; Zoolfakar, A.S.; Rani, R.A.; Zhuiykov, S.; O'Mullane, A.P.; Kalantar-zadeh, K. The anodized crystalline $\mathrm{WO}_{3}$ nanoporous network with enhanced electrochromic properties. Nanoscale 2012, 4, 5980-5988. [CrossRef] [PubMed]

15. Jiang, Q.L.; Liu, F.Q.; Li, T.; Xu, T. Fast and low voltage-driven solid-state electrochromics using 3-D conductive FTO nanobead electrodes. J. Mater. Chem. C 2014, 2, 618-621. [CrossRef]

16. Li, M.; Wei, Y.X.; Zheng, J.M.; Zhu, D.; Xu, C.Y. Highly contrasted and stable electrochromic device based on well-matched viologen and triphenylamine. Org. Electron. 2014, 15, 428-434. [CrossRef]

17. Eh, A.L.-S.; Tan, A.W.M.; Cheng, X.; Magdassi, S.; Lee, P.S. Recent advances in flexible electrochromic devices: Prerequisites, challenges, and prospects. Energy Technol. 2018, 6, 33-45. [CrossRef]

18. Huang, J.H.; Hsu, M.H.; Hsiao, Y.S.; Chen, P.L.; Yu, P.C.; Chu, C.W. Performance of chromophore-type electrochromic devices employing indium tin oxide nanorod optical amplification. Sol. Energy Mater. Sol. Cells 2012, 98, 191-197. [CrossRef]

19. Wang, X.; Liu, B.; Tang, J.; Dai, G.; Dong, B.; Cao, L.; Gao, R.; Su, G. Preparation of Ni(OH $)_{2} / \mathrm{TiO}_{2}$ porous film with novel structure and electrochromic property. Sol. Energy Mater. Sol. Cells 2019, 191, 108-116. [CrossRef]

20. Lee, K.-C.; Chang-Jian, C.-W.; Cho, E.-C.; Huang, J.-H.; Lin, W.-T.; Ho, B.-C.; Chou, J.-A.; Hsiao, Y.-S. Surface modification of $\mathrm{Ni}(\mathrm{OH})_{2}$ nanosheets with PEDOT:PSS for supercapacitor and bendable electrochromic applications. Sol. Energy Mater. Sol. Cells 2019, 195, 1-11. [CrossRef] 
21. Deng, B.; Hsu, P.-C.; Chen, G.; Chandrashekar, B.N.; Liao, L.; Ayitimuda, Z.; Wu, J.; Guo, Y.; Lin, L.; Zhou, Y.; et al. Roll-to-roll encapsulation of metal nanowires between graphene and plastic substrate for high-performance flexible transparent electrodes. Nano Lett. 2015, 15, 4206-4213. [CrossRef] [PubMed]

22. Xu, S.; Li, X.; Ou, Y.; Xu, Q.; Zhang, X.M.; Xu, J.; Weng, J. Ultra-large optical modulation of a size-tunable flexible electrochromic honeycomb mesoporous tungsten oxide film. Inorg. Chem. Front. 2019, 6, 680-686. [CrossRef]

23. Cai, G.; Darmawan, P.; Cui, M.; Wang, J.; Chen, J.; Magdassi, S.; Lee, P.S. Highly stable transparent conductive silver grid/PEDOT:PSS electrodes for integrated bifunctional flexible electrochromic supercapacitors. Adv. Energy Mater. 2016, 6, 1501882. [CrossRef]

24. Wang, J.L.; Lu, Y.R.; Li, H.H.; Liu, J.W.; Yu, S.H. Large area co-assembly of nanowires for flexible transparent smart windows. J. Am. Chem. Soc. 2017, 139, 9921-9926. [CrossRef] [PubMed]

25. Che, B.; Zhou, D.; Li, H.; He, C.; Liu, E.; Lu, X. A highly bendable transparent electrode for organic electrochromic devices. Org. Electron. 2019, 66, 86-93. [CrossRef]

26. Lehtimaki, S.; Suominen, M.; Damlin, P.; Tuukkanen, S.; Kvarnstrom, C.; Lupo, D. Preparation of supercapacitors on flexible substrates with electrodeposited PEDOT/graphene composites. ACS Appl. Mater. Interfaces 2015, 7, 22137-22147. [CrossRef] [PubMed]

27. Singh, R.; Tharion, J.; Murugan, S.; Kumar, A. ITO-free solution-processed flexible electrochromic devices based on PEDOT:PSS as transparent conducting electrode. ACS Appl. Mater. Interfaces 2017, 9, 19427-19435. [CrossRef]

28. Bi, Z.; Li, X.; He, X.; Chen, Y.; Xu, X.; Gao, X. Integrated electrochromism and energy storage applications based on tungsten trioxide monohydrate nanosheets by novel one-step low temperature synthesis. Sol. Energy Mater. Sol. Cells 2018, 183, 59-65. [CrossRef]

29. Bogati, S.; Georg, A.; Graf, W. Photoelectrochromic devices based on sputtered $\mathrm{WO}_{3}$ and $\mathrm{TiO}_{2}$ films. Sol. Energy Mater. Sol. Cells 2017, 163, 170-177. [CrossRef]

30. Dokouzis, A.; Theodosiou, K.; Leftheriotis, G. Assessment of the long-term performance of partly covered photoelectrochromic devices under insolation and in storage. Sol. Energy Mater. Sol. Cells 2018, 182, 281-293. [CrossRef]

31. Azam, A.; Kim, J.; Park, J.; Novak, T.G.; Tiwari, A.P.; Song, S.H.; Kim, B.; Jeon, S. Two-dimensional $\mathrm{WO}_{3}$ nanosheets chemically converted from layered $\mathrm{WS}_{2}$ for high-performance electrochromic devices. Nano Lett. 2018, 18, 5646-5651. [CrossRef] [PubMed]

32. Yang, P.; Sun, P.; Chai, Z.; Huang, L.; Cai, X.; Tan, S.; Song, J.; Mai, W. Large-scale fabrication of pseudocapacitive glass windows that combine electrochromism and energy storage. Angew. Chem. Int. Ed. 2014, 53, 11935-11939. [CrossRef] [PubMed]

33. Leftheriotis, G.; Syrrokostas, G.; Yianoulis, P. Development of photoelectrochromic devices for dynamic solar control in buildings. Sol. Energy Mater. Sol. Cells 2010, 94, 2304-2313. [CrossRef]

34. Xia, X.; Ku, Z.; Zhou, D.; Zhong, Y.; Zhang, Y.; Wang, Y.; Huang, M.J.; Tu, J.; Fan, H.J. Perovskite solar cell powered electrochromic batteries for smart windows. Mater. Horiz. 2016, 3, 588-595. [CrossRef]

35. Leftheriotis, G.; Syrrokostas, G.; Yianoulis, P. "Partly covered" photoelectrochromic devices with enhanced coloration speed and efficiency. Sol. Energy Mater. Sol. Cells 2012, 96, 86-92. [CrossRef]

36. Leftheriotis, G.; Syrrokostas, G.; Yianoulis, P. Photocoloration efficiency and stability of photoelectrochromic devices. Solid State Ion. 2013, 231, 30-36. [CrossRef]

37. Xu, Z.; Li, W.; Huang, J.; Guo, X.; Liu, Q.; Yu, R.; Miao, W.; Zhou, B.; Guoa, W.; Liu, X. Flexible, controllable and angle-independent photoelectrochromic display enabled by smart sunlight management. Nano Energy 2019, 63, 103830. [CrossRef]

38. Tong, Z.Q.; Tian, Y.L.; Zhang, H.M.; Li, X.G.; Ji, J.Y.; Qu, H.Y.; Li, N.; Zhao, J.P.; Li, Y. Recent advances in multifunctional electrochromic energy storage devices and photoelectrochromic devices. Sci. Chin. Chem. 2017, 60, 13-37. [CrossRef]

39. Thakur, V.K.; Ding, G.; Ma, J.; Lee, P.S.; Lu, X. Hybrid materials and polymer electrolytes for electrochromic device applications. Adv. Mater. 2012, 24, 4071-4096. [CrossRef]

40. Deepa, M.; Sharma, R.; Basu, A.; Agnihotry, S.A. Effect of oxalic acid dihydrate on optical and electrochemical properties of sol-gel derived amorphous electrochromic $\mathrm{WO}_{3}$ films. Electrochim. Acta 2005, 50, 3545-3555. [CrossRef] 
41. Subrahmanyam, A.; Karuppasamy, A. Optical and electrochromic properties of oxygen sputtered tungsten oxide $\left(\mathrm{WO}_{3}\right)$ thin films. Sol. Energy Mater. Sol. Cells 2007, 91, 266-274. [CrossRef]

42. Liang, L.; Zhang, J.J.; Zhou, Y.Y.; Xie, J.F.; Zhang, X.D.; Guan, M.L.; Pan, B.C.; Xie, Y. High-performance flexible electrochromic device based on facile semiconductor-to-metal transition realized by $\mathrm{WO}_{3}$ center dot $2 \mathrm{H}_{2} \mathrm{O}$ ultrathin nanosheets. Sci. Rep. 2013, 3, 1936. [CrossRef] [PubMed]

43. Cai, G.F.; Darmawan, P.; Cui, M.Q.; Chen, J.W.; Wang, X.; Eh, A.L.S.; Magdassi, S.; Lee, P.S. Inkjet-printed all solid-state electrochromic devices based on $\mathrm{NiO} / \mathrm{WO}_{3}$ nanoparticle complementary electrodes. Nanoscale 2016, 8, 348-357. [CrossRef] [PubMed]

44. Deepa, M.; Singh, D.P.; Shivaprasad, S.M.; Agnihotry, S.A. A comparison of electrochromic properties of sol-gel derived amorphous and nanocrystalline tungsten oxide films. Curr. Appl. Phys. 2007, 7, 220-229. [CrossRef]

(C) 2020 by the authors. Licensee MDPI, Basel, Switzerland. This article is an open access article distributed under the terms and conditions of the Creative Commons Attribution (CC BY) license (http://creativecommons.org/licenses/by/4.0/). 